\title{
Aberrant gene expression in mucosa adjacent to tumor reveals a molecular crosstalk in colon cancer
}

Rebeca Sanz-Pamplona ${ }^{1}$, Antoni Berenguer ${ }^{1}$, David Cordero ${ }^{1}$, David G Molleví ${ }^{2}$, Marta Crous-Bou', Xavier Sole ${ }^{1}$, Laia Paré-Brunet ${ }^{1}$, Elisabet Guino ${ }^{1}$, Ramón Salazar ${ }^{2,3}$, Cristina Santos ${ }^{2,3}$, Javier de Oca ${ }^{4,5}$, Xavier Sanjuan 6 , Francisco Rodriguez-Moranta ${ }^{7}$ and Victor Moreno ${ }^{1,5^{*}}$

\begin{abstract}
Background: A colorectal tumor is not an isolated entity growing in a restricted location of the body. The patient's gut environment constitutes the framework where the tumor evolves and this relationship promotes and includes a complex and tight correlation of the tumor with inflammation, blood vessels formation, nutrition, and gut microbiome composition. The tumor influence in the environment could both promote an anti-tumor or a pro-tumor response.

Methods: A set of 98 paired adjacent mucosa and tumor tissues from colorectal cancer (CRC) patients and 50 colon mucosa from healthy donors (246 samples in total) were included in this work. RNA extracted from each sample was hybridized in Affymetrix chips Human Genome U219. Functional relationships between genes were inferred by means of systems biology using both transcriptional regulation networks (ARACNe algorithm) and protein-protein interaction networks (BIANA software).
\end{abstract}

Results: Here we report a transcriptomic analysis revealing a number of genes activated in adjacent mucosa from CRC patients, not activated in mucosa from healthy donors. A functional analysis of these genes suggested that this active reaction of the adjacent mucosa was related to the presence of the tumor. Transcriptional and protein-interaction networks were used to further elucidate this response of normal gut in front of the tumor, revealing a crosstalk between proteins secreted by the tumor and receptors activated in the adjacent colon tissue; and vice versa. Remarkably, Slit family of proteins activated ROBO receptors in tumor whereas tumor-secreted proteins transduced a cellular signal finally activating AP-1 in adjacent tissue.

Conclusions: The systems-level approach provides new insights into the micro-ecology of colorectal tumorogenesis. Disrupting this intricate molecular network of cell-cell communication and pro-inflammatory microenvironment could be a therapeutic target in CRC patients.

Keywords: Colorectal cancer, Network, Microenvironment, Molecular crosstalk, Systems biology

\footnotetext{
* Correspondence: v.moreno@iconcologia.net

${ }^{1}$ Unit of Biomarkers and Susceptibility, Catalan Institute of Oncology (ICO), Bellvitge Biomedical Research Institute (IDIBELL) and CIBERESP, L'Hospitalet de Llobregat, Barcelona, Spain

${ }^{5}$ Department of Clinical Sciences, Faculty of Medicine, University of Barcelona (UB), Av. Gran Vía 199-203, 08908 L'Hospitalet de Llobregat, Barcelona, Spain Full list of author information is available at the end of the article
} 


\section{Background}

Colorectal cancer $(\mathrm{CRC})$ is a complex disease in which many genes, proteins, and molecular processes are implicated. Proteins do not work independently in a tumor cell, but are organized into co-regulated units or pathways that perform a common biological function [1]. Relevant molecular mechanisms involved in cancer are gene regulation, signaling, cell metabolism, and the connections between them, among others [2]. In addition to the tumor cell intrinsic complexity, increasing data support the main role of tumor microenvironment in the mechanisms of CRC progression [3-5]. Tumor microenvironment is composed by a heterogeneous population of stromal cells such as fibroblasts and immune cells, extracellular matrix components and secreted factors. All these components work orchestrated by molecular transducers like integrins engaging cell-cell and cell-matrix signaling that in turn enhance tumor growth [6].

Besides, a colorectal tumor is not an isolated entity growing in a restricted location of the body. An active communication exists not only between different cell communities within the tumor bulk but also between the tumor and the non-tumor distant mucosa. Hence, the patient's gut environment constitutes the framework where the tumor evolves and this relationship promotes and includes a complex and tight correlation with inflammation, blood vessels formation, nutrition and gut microbiome composition [7]. Consequently, studying the micro-ecology context of a tumor is central to understand colorectal carcinogenesis. The tumor influence on environment could both promote an anti-tumor and a pro-tumor response. Some microenvironments, particularly those associated with tissue injury, are favorable for progression of mutant cells, whereas others restrict it. Cancer cells can also instruct surrounding tissues to undergo changes that promote malignancy [8].

Field cancerization or the field-effect is a theory first described by Slaughter et al. in oral carcinoma [9]. In the initial phase of the multistep carcinogenesis, a stem cell acquires genetic alterations and forms a "patch", a clonal unit of altered daughter cells. Further alterations convert the "patch" into a field of pre-neoplastic cells. Although only one cell becomes tumoral, the remaining field (adjacent mucosa) continues in a "pre-neoplasticstate" composed of morphologically normal, but biologically altered epithelial cells. Since this field is a pre-tumor site predisposed towards development of cancer, this hypothesis could explain local recurrences after surgery [10].

Understanding the complex ways in which cancer cells interact with their surroundings, both locally in the tumor organ and systemically in the body as a whole has implications for effective cancer prevention and therapy. In contrast to the gene-centric view, a systems biology approach (defined as the analysis of the molecular relationship between genes and proteins as a whole) can be useful to depict a global view of the cancer disease not only as a tumor cell but as an intricate systemic disease [11].

In this study, mRNA expression from paired tumor $(\mathrm{T})$ and adjacent mucosa from CRC patients (A) and mRNA from mucosa healthy donors $(\mathrm{H})$ were measured using microarrays. The inclusion of samples from healthy subjects has allowed us assessing whether adjacent mucosa from colon cancer patients differs from healthy donors' mucosa possibly due to the tumor presence. Indeed, a number of differentially expressed genes (DEG) were found between these two entities (A vs. H). Considering their level of expression in tumor tissues, these DEGs were classified as "Tumor-like", "Trend" or "Adjacentspecific" (A vs. T) patterns. To explain the mechanisms that regulate these patterns of differential expression, networks mimicking transcription regulation were used to search for those transcription factors directly influencing DEG. Then, a systems biology approach using PPIN was applied to describe a crosstalk between cytokines and other proteins secreted by the tumor and receptors activated in the adjacent colon tissue; and vice versa, providing new insights into the micro-ecology of colorectal tumorigenesis. Finally, relevant cytokines and receptors up-regulated in tumor tissue were identified comparing $\mathrm{T}$ vs. $\mathrm{H}$ expression (Figure 1). Further elucidation of these interactions could be helpful in the development of novel therapeutic strategies oriented to disrupt this molecular crosstalk.

\section{Results}

\section{Characterization of differentially expressed genes} between adjacent and healthy mucosa

A principal component analysis (PCA) was done to explore the variability of the transcriptomic data from our 246 samples (Figure 2A). As expected, tumor samples appeared as an independent cluster ( $\mathrm{T}$ in red). Surprisingly, adjacent paired mucosa (A in blue) were also clearly separated from healthy mucosa ( $\mathrm{H}$ in green), reflecting a large number of differentially expressed genes (DEG) between them. A total of 895 genes were differentially expressed at FDR $<1 \%$ and $\log 2$ mean difference $>1$ between adjacent and healthy mucosa (Additional file 1: Table S1). Interestingly, $88 \%$ of these genes were over-expressed in adjacent mucosa (Figure 2B).

The functional enrichment analysis of these genes identified the classical pathways involved in cancer and were highlighted by a significant enrichment of functions related to Inhibition of matrix metalloproteinases, Cell adhesion molecules, cytokine-cytokine receptor interaction, TGF-beta signaling pathway, integrin signaling pathway, complement and coagulation cascades, wound healing, response to external stimulus, inflammatory response and soluble fraction, among others (see 


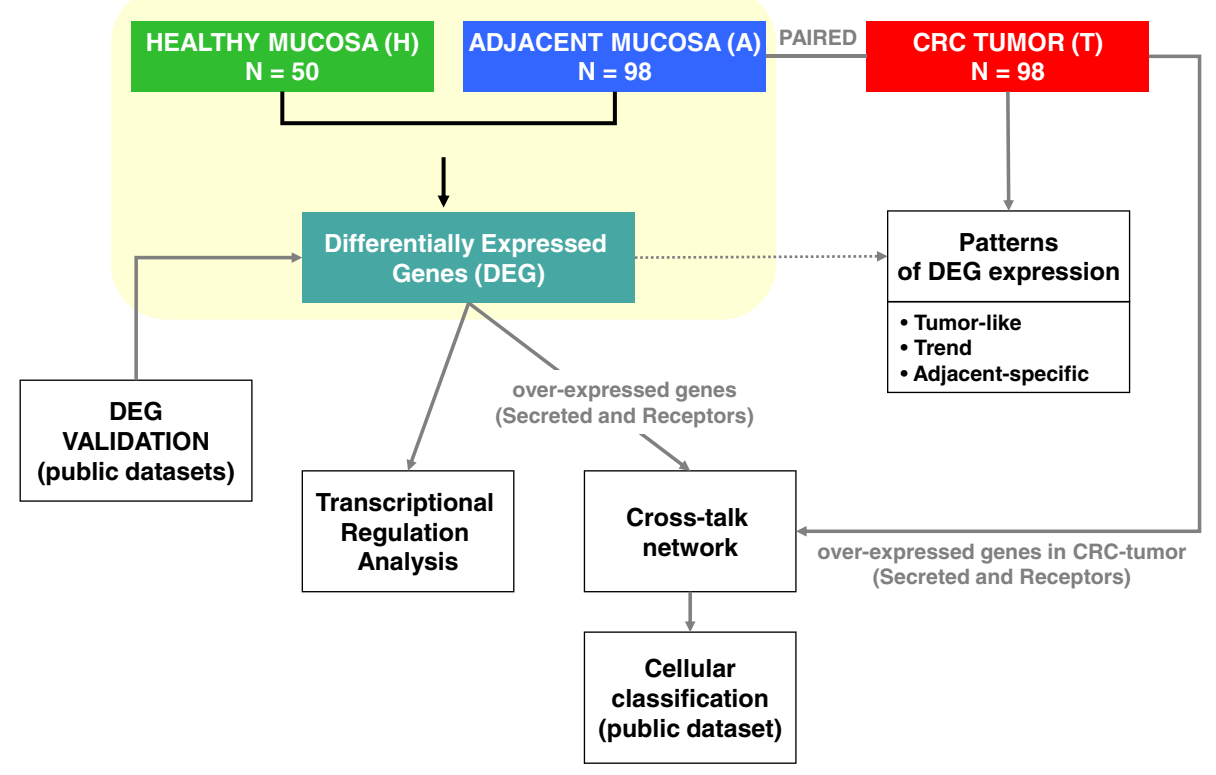

Figure 1 Work flow chart. The central core of the analysis is the comparison between adjacent mucosa and healthy mucosa at transcriptomic (gene expression data) and transcriptional (regulatory network) level. Independent public datasets were used to validate the results. In a second step, tumor tissue was used to search for different DEG patterns. Finally, a crosstalk network was inferred to decipher molecular communication between the tumor and the adjacent gut underlying DEG. Public data was used to elaborate a cellular classification of genes implicated in the crosstalk.

complete list in Additional file 2: Table S2, Additional file 3: Table S3 and Additional file 4: Figure S1). This functional analysis suggested an active reaction of the adjacent mucosa related to the presence of the tumor or a more passive reaction induced by factors released from the tumor.

Public transcriptomic data analyzing adjacent and healthy mucosa were used to validate the list of DEG. As a result, $60 \%$ of the genes were validated at FDR $1 \%$. At FDR 5\%, $91 \%$ of the genes were validated (Additional file 5: Table S4 and Additional file 4: Figure S2). These results should be interpreted with caution because each sample type was analyzed in different experiments and, though we normalized the data jointly, we cannot exclude strong batch or laboratory effects. We could not find a dataset like ours, in which healthy and adjacent colon mucosa were analyzed simultaneously.

Figure 3A shows a hierarchical clustering performed with the set of DEG between adjacent mucosa (A) and
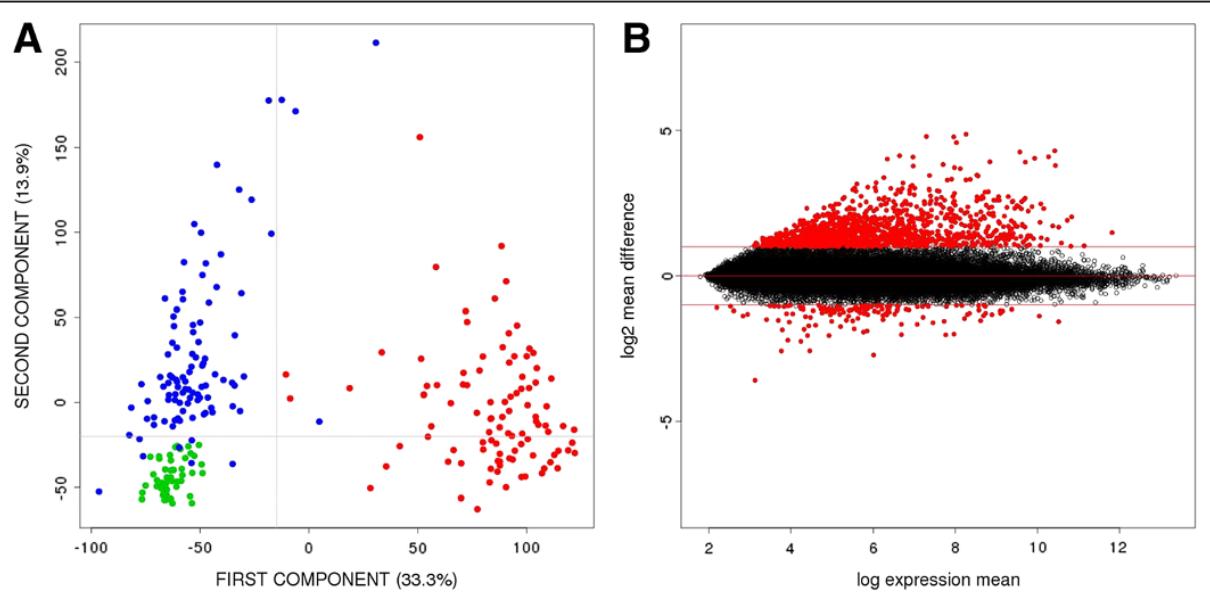

Figure 2 Gene expression differences between adjacent and healthy mucosa samples. A. PCA scatter plot representing the dispersion of the samples based on their gene expression levels. Tumor samples (red), adjacent mucosa samples (blue) and samples from healthy donors (green) were plotted in $1^{\text {st }}$ and $2^{\text {nd }}$ principal components. B. MA Plot representing gene expression differences between adjacent and healthy mucosa samples. In red, those probes with a FDR $<1 \%$ and log2 mean difference $>1$. 

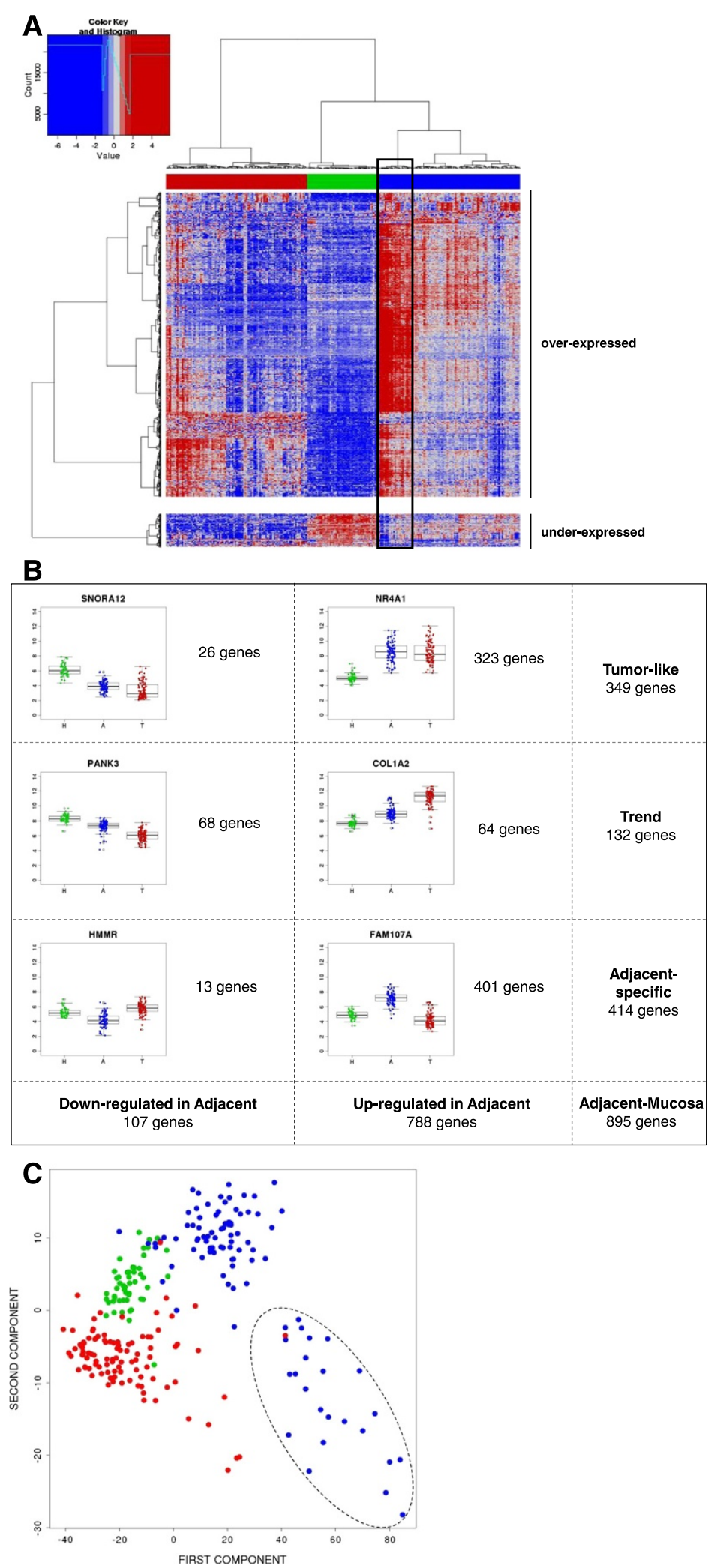

Figure 3 (See legend on next page.) 
(See figure on previous page.)

Figure 3 DEG characterization. A. Hierarchical clustering of 1230 over-expressed and 136 under-expressed probes that correspond to 788 and 107 genes respectively classifying the 246 tissue samples into three clusters of healthy mucosa (green), tumors (red) and adjacent mucosa (blue). Highlighted in black, the group of 24 adjacent samples showing an extreme phenotype. B. Representative DEG patterns are displayed. DEG between adjacent and mucosa were classified as "Tumor-like", "Trend" and "Adjacent-specific" genes. C. PCA using "Adjacent-specific" DEG. Tumor samples $(T)$ are painted in red, adjacent samples $(A)$ in blue and healthy mucosa $(H)$ in green. The 24 adjacent samples showing an extreme phenotype are circled with a dot line.

healthy mucosa $(\mathrm{H})$. Interestingly, the three different tissues were perfectly classified, including the tumors (T) that did not participate in the gene selection. Regarding genes, three patterns of expression were identified as shown in Figure 3B: a) "Tumor-like" $(\mathrm{A}=\mathrm{T}>\mathrm{H}$ or $\mathrm{H}>\mathrm{A}=\mathrm{T}$ ) when genes in $\mathrm{A}$ had similar pattern as $\mathrm{T}$ (349 genes); b) "Trend" ( $\mathrm{T}>\mathrm{A}>\mathrm{H}$ or $\mathrm{H}>\mathrm{A}>\mathrm{T}$ ) when genes in $\mathrm{A}$ had an intermediate expression between $\mathrm{H}$ and T (132 genes); and c) "Adjacent-specific" $(\mathrm{A}<(\mathrm{T}, \mathrm{H})$ or $A>(T, H))$, when genes were specifically de-regulated in $\mathrm{A}$ when compared to either $\mathrm{T}$ or $\mathrm{H}$, irrespective of the relationship between $\mathrm{T}$ and $\mathrm{H}$ (414 genes). The size of this latter group was a surprise that lead us to explore in detail a crosstalk between the tumor and the adjacent mucosa.

Regarding enriched functions for these gene patterns, Tumor-like functions included AP-1 transcription factor network, COX reactions or activation of $A P-1$, whereas Adjacent-specific functions were enriched in axon guidance, PPAR signaling pathway or BMP2 signaling pathway, among others. These results suggest different functions for each gene expression pattern, though Integrin signaling pathway, complement cascade, adhesion or Interferon signaling were functions shared by the two patterns (see complete list in Additional file 6: Table S5).

Adjacent mucosa samples appeared divided into two groups in the hierarchical clustering analysis (Figure 3A). The smallest of them, with 24 samples, was characterized by high expression in most of adjacent-specific genes. A PCA performed with these adjacent-specific genes showed that the second component was capturing the specificity of this sample cluster and that adjacent mucosa were more similar to tumor than to healthy mucosa (Figure $3 \mathrm{C}$ ). In fact, the original PCA analysis with all genes also identified these adjacent mucosa samples as highly variable in the second component (Figure 2A).

These clusters were not associated with the clinical parameters gender, age and tumor progression neither with technical parameters RNA integrity value (RIN), 260/230 ratio and plate. In addition, a functional analysis including differentially expressed genes between these two clusters did not show specific functions but essentially those described as characteristic of adjacent mucosa. These results suggest that the smaller cluster of adjacent samples was just an extreme phenotype of these samples. Interestingly, this pattern was also observed in the validation dataset (see heatmap in Additional file 4: Figure S2).

\section{Transcriptional regulation of differentially expressed genes between adjacent and healthy mucosa}

We hypothesized that this differential expression could be triggered by a transcriptional program, activated only in adjacent mucosa by the presence of the tumor, and normally silenced in healthy mucosa. This hypothesis was supported by the GSEA results, in which 312 transcription factors motifs were found to be statistically associated with the adjacent mucosa phenotype (nominal $\mathrm{p}$-value $<0.01$ ) but none was found associated to healthy mucosa phenotype (Additional file 3: Table S3).

To further explore this hypothesis, transcriptional networks were inferred and compared using gene expression data of adjacent and healthy mucosa (see Additional file 4: Figure S3). Venn diagram in Figure 4A shows the overlap between nodes of each network. The vast majority of healthy mucosa nodes were also active in adjacent mucosa network whereas 3120 new nodes appeared specific to the adjacent mucosa and 668 nodes disappeared from the network. As expected, DEG between adjacent and healthy mucosa were overrepresented in the new active nodes of the adjacent mucosa network (empirical p-value $<10^{-4}$ ) suggesting that DEG are not only performing common functions but also co-regulated in a sub-transcriptional network not active in healthy mucosa samples. Out of 895 DEG, $60(13 \%)$ were transcription factors (TF), and random re-sampling of genes among the complete dataset revealed that DEG were significantly enriched in TF (empirical p-value $<0.001)$. Among these $60 \mathrm{TF}, 35$ were specific of the adjacent mucosa transcriptional network.

TF were ranked taking into account the total number of their targets (degree) and the proportion of targets in our DEG list. This rank suggested sub-networks specifically active in adjacent mucosa tissue. TF with higher rank were more specific of adjacent mucosa, and showed higher values of eccentricity (a topological network measure of the spreading of a node in the network) and lower values of closeness centrality (Table 1 ).

Genes from the AP-1 complex (Fosb and Jun) ranked first in the TF list. The AP-1 subunits Fos, Junb, Mafb and Atf3 also appeared in the list. Previous GSEA analysis also had revealed as most significant motive "Genes 


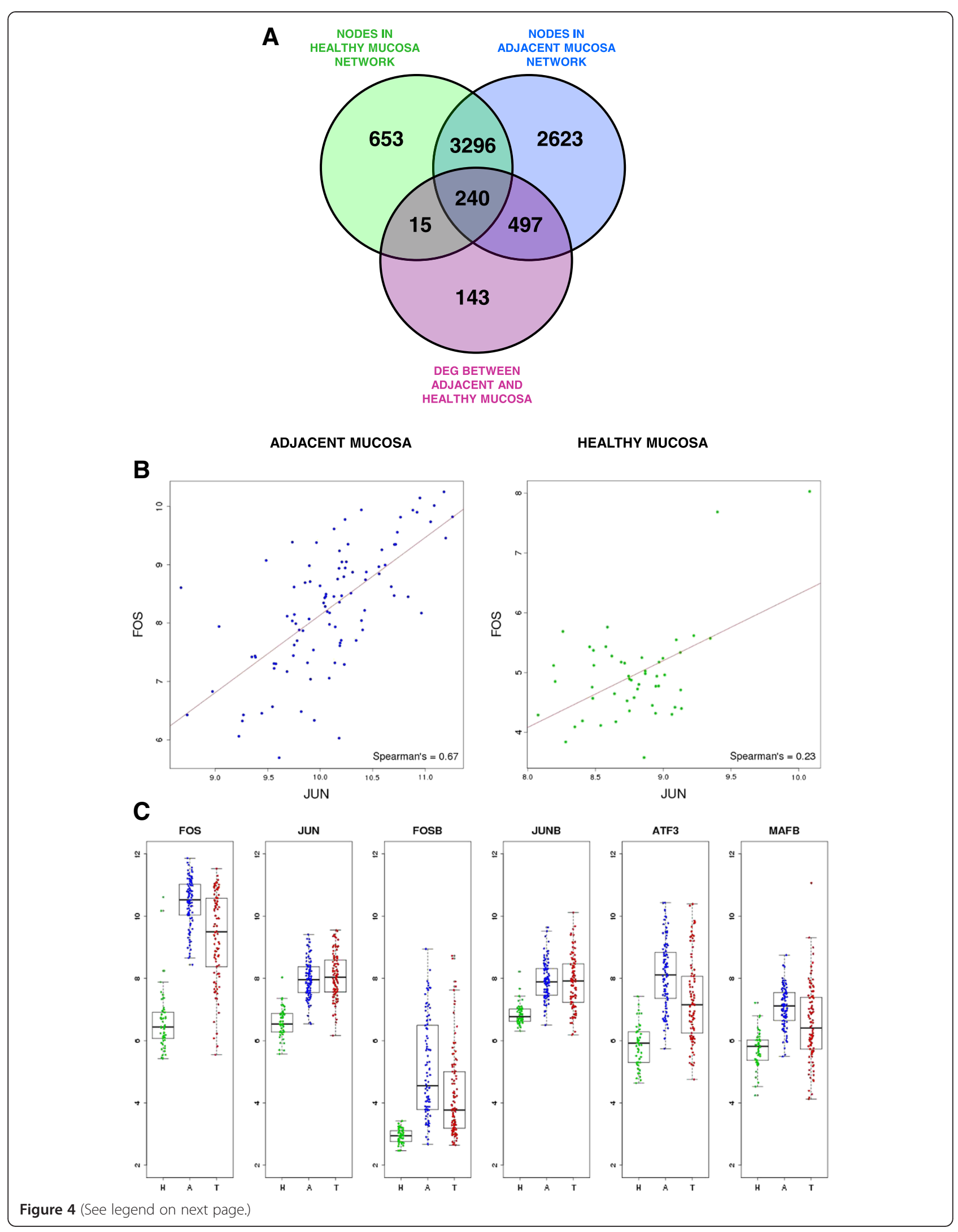


with promoter regions [ $-2 \mathrm{~kb}, 2 \mathrm{~kb}]$ around transcription start site containing the motif TGACTCANNSKN which matches annotation for JUN" (p-value $=0.002$, and FDR $\mathrm{q}$-value $=0.015$, Additional file 4: Figure S4). A high correlation existed between the expression of Jun and Fos AP-1 subunits in adjacent mucosa but not in healthy mucosa (Spearman's correlation 0.67 and 0.23 respectively; Figure 4B). Interestingly, these TF belonged to the "tumor-like" genes pattern (Figure 4C). Fos, Jun, Fosb and Junb did not appear in healthy mucosa transcriptional network highlighting their idiosyncratic role in adjacent mucosa. The family of transcription factors $N R 4 A 1, N R 4 A 2$ and $N R 4 A 3$ also ranked in top positions. Other TF such as GLI3, BCN2, EBF1 and ZEB1 were also significant because of their high rank in the network and large number of DEG targets.

\section{Deciphering a crosstalk between adjacent mucosa and tumor through a protein-protein interaction network}

Changes in adjacent mucosa not detected in healthy mucosa might be a direct response in front of tumor stimulus based on a physical crosstalk between the cells (Figure 1). This molecular communication could be through the direct interaction between secreted proteins and their corresponding membrane receptors. The following strategy was applied to identify interactions compatible with this hypothesis: 1) Search for over-expressed genes in tumors compared to healthy mucosa in addition to previous DEG. 2) Identify those that code for secreted proteins and membrane receptors. 3) Construct a protein interaction network with the selected genes. 4) Identify interaction pairs that reflect cellular communication in both directions: from tumor to adjacent (efferent pathway) and vice versa (afferent pathway).

From the 788 over-expressed genes in adjacent mucosa vs. healthy mucosa, $324(41 \%)$ corresponded to secreted $(n=111)$ or membrane $(n=213)$ genes. In addition, 442 genes (250 secreted and 192 membrane) over-expressed in tumors were included in the analysis. A level 0 (only direct interactions) protein-protein interaction network was retrieved using the 766 up-regulated secreted/membrane genes in adjacent and tumor samples as input. The resulting network included 291 nodes connected by 596 interactions, the majority of them integrated in a giant component (Figure 5A). A functional analysis of this network revealed cell adhesion, response to external stimulus, response to wounding, and anatomical structure development as the most statistically significant functions (Additional file 7: Table S6).

A curated analysis of the network revealed 84 crosstalk interactions (Table 2), 61 of them efferent (tumor secreted proteins linked to a receptor in adjacent mucosa tissue), and 23 afferent (adjacent mucosa secreted proteins linked to a receptor in tumor). Figure $5 \mathrm{~B}$ shows an abstraction of the original network restricted to crosstalk interactions. It is remarkable that 6 out of 23 afferent interactions (26\%) included members of the Slit family of secreted proteins, which emerged as relevant players in tumor crosstalk determining the adjacent mucosa response. In the network, Slit2 and Slit3 were redundantly activating Robo1, Robo2, Robo4 and ITGA1 receptors in tumor. Slit family followed an adjacent-specific pattern of expression (see Figure 6A). Due to its importance, and as a proof of concept of the overall strategy of gene selection, inmunohistochemical staining was done to asses the protein expression of Slit2 and the receptor Robo2. Slit2 was expressed in adjacent epithelial cells and also in stromal cancer cells. Robo2 was expressed in both epithelial and stromal cells in cancer tissue but not in adjacent tissue (Figure 6B). Other interesting afferent crosstalk pairs involved LRP8 receptor in tumor activated by a double stimulus of RELN and CLU proteins secreted by adjacent mucosa, and VIP, an intestinal peptide that causes vasodilatation, linked to MME receptor in tumor cells.

Efferent interactions were more numerous and included interleukins (IL-8), extracellular-matrix components (Fibronectin, Collagen) or molecules related to invasion like SPARC linked with receptors such as integrins or complement receptors (see Table 2 for specific pairs). Interestingly, the vascular endothelial growth factor receptor NRP2, over-expressed in adjacent mucosa, interacted with a plethora of candidate activating secreted factors from tumors such as VEGFA or SEMA3F. Another interesting finding was the over-expression of LIF in tumor, whose receptor LIFR was over-expressed in adjacent mucosa but not in the tumor. These results were highly indicative of an active crosstalk between cells in the gut microenvironment that triggers an intra-cellular signaling response. The protein-protein interaction network also revealed autocrine signals within tumor or adjacent mucosa. For example, the vascular endothelial growth factor receptor FLT1 was found linked with its ligand VEGFA, both over-expressed in tumor samples. 
Table 1 List of transcription factors differentially expressed between adjacent and healthy mucosa samples

\begin{tabular}{|c|c|c|c|c|c|c|c|}
\hline Gene symbol & Connections & DEG connections & Rank & P-value & Eccentricity & Closenness centrality & Healthy mucosa network \\
\hline FOSB & 4 & 4 & 1.000 & $<1.00 \mathrm{E}-04$ & 9 & 0.209 & $\mathrm{NO}$ \\
\hline JUN & 2 & 2 & 1.000 & $<1.00 \mathrm{E}-04$ & 11 & 0.151 & NO \\
\hline NR4A2 & 5 & 5 & 1.000 & $<1.00 \mathrm{E}-04$ & 9 & 0.204 & NO \\
\hline OSR2 & 12 & 12 & 1.000 & $<1.00 \mathrm{E}-04$ & 8 & 0.234 & NO \\
\hline ZBTB16 & 1 & 1 & 1.000 & $<1.00 \mathrm{E}-04$ & 9 & 0.200 & NO \\
\hline EGR2 & 10 & 9 & 0.900 & $<1.00 \mathrm{E}-04$ & 8 & 0.247 & NO \\
\hline NR4A3 & 9 & 8 & 0.889 & $<1.00 \mathrm{E}-04$ & 8 & 0.249 & NO \\
\hline EBF1 & 162 & 143 & 0.883 & $<1.00 \mathrm{E}-04$ & 7 & 0.294 & YES \\
\hline HEY2 & 24 & 21 & 0.875 & $<1.00 \mathrm{E}-04$ & 8 & 0.266 & NO \\
\hline NR4A1 & 16 & 14 & 0.875 & $<1.00 \mathrm{E}-04$ & 8 & 0.240 & $\mathrm{NO}$ \\
\hline PRRX1 & 30 & 26 & 0.867 & $<1.00 \mathrm{E}-04$ & 7 & 0.289 & NO \\
\hline EGR1 & 13 & 11 & 0.846 & $<1.00 \mathrm{E}-04$ & 9 & 0.217 & YES \\
\hline FOS & 6 & 5 & 0.833 & $<1.00 \mathrm{E}-04$ & 10 & 0.178 & NO \\
\hline JUNB & 5 & 4 & 0.800 & $<1.00 \mathrm{E}-04$ & 10 & 0.178 & NO \\
\hline MEOX2 & 75 & 60 & 0.800 & $<1.00 \mathrm{E}-04$ & 7 & 0.303 & NO \\
\hline ZFPM2 & 133 & 106 & 0.797 & $<1.00 \mathrm{E}-04$ & 7 & 0.296 & NO \\
\hline ERG & 76 & 60 & 0.789 & $<1.00 \mathrm{E}-04$ & 8 & 0.287 & NO \\
\hline TSHZ2 & 109 & 85 & 0.780 & $<1.00 \mathrm{E}-04$ & 7 & 0.302 & NO \\
\hline FOXC1 & 27 & 21 & 0.778 & $<1.00 \mathrm{E}-04$ & 8 & 0.268 & NO \\
\hline HLF & 84 & 65 & 0.774 & $<1.00 \mathrm{E}-04$ & 7 & 0.301 & NO \\
\hline MEIS2 & 133 & 100 & 0.752 & $<1.00 \mathrm{E}-04$ & 8 & 0.305 & NO \\
\hline CREB5 & 32 & 24 & 0.750 & $<1.00 \mathrm{E}-04$ & 8 & 0.278 & NO \\
\hline PRDM6 & 83 & 62 & 0.747 & $<1.00 \mathrm{E}-04$ & 7 & 0.293 & NO \\
\hline GLIS2 & 79 & 58 & 0.734 & $<1.00 \mathrm{E}-04$ & 7 & 0.302 & NO \\
\hline HAND2 & 138 & 101 & 0.732 & $<1.00 \mathrm{E}-04$ & 7 & 0.289 & NO \\
\hline EGR3 & 11 & 8 & 0.727 & $<1.00 \mathrm{E}-04$ & 8 & 0.263 & NO \\
\hline SOX18 & 40 & 29 & 0.725 & $<1.00 \mathrm{E}-04$ & 7 & 0.274 & NO \\
\hline ZNF423 & 79 & 57 & 0.722 & $<1.00 \mathrm{E}-04$ & 8 & 0.303 & YES \\
\hline $\mathrm{PHOX} 2 \mathrm{~B}$ & 60 & 42 & 0.700 & $<1.00 \mathrm{E}-04$ & 8 & 0.275 & YES \\
\hline KLF7 & 133 & 92 & 0.692 & $<1.00 \mathrm{E}-04$ & 7 & 0.313 & NO \\
\hline GLI3 & 217 & 150 & 0.691 & $<1.00 \mathrm{E}-04$ & 7 & 0.325 & NO \\
\hline MEIS1 & 113 & 77 & 0.681 & $<1.00 \mathrm{E}-04$ & 8 & 0.301 & YES \\
\hline KLF2 & 15 & 10 & 0.667 & $<1.00 \mathrm{E}-04$ & 8 & 0.261 & YES \\
\hline TSHZ3 & 80 & 52 & 0.650 & $<1.00 \mathrm{E}-04$ & 8 & 0.302 & YES \\
\hline NKX2-3 & 75 & 47 & 0.627 & $<1.00 \mathrm{E}-04$ & 8 & 0.290 & NO \\
\hline BNC2 & 252 & 148 & 0.587 & $<1.00 \mathrm{E}-04$ & 7 & 0.334 & $\mathrm{NO}$ \\
\hline PITX2 & 26 & 15 & 0.577 & $<1.00 \mathrm{E}-04$ & 9 & 0.244 & YES \\
\hline PRDM8 & 70 & 40 & 0.571 & $<1.00 \mathrm{E}-04$ & 7 & 0.304 & YES \\
\hline NR2F2 & 141 & 78 & 0.553 & $<1.00 \mathrm{E}-04$ & 7 & 0.334 & YES \\
\hline TSC22D3 & 29 & 16 & 0.552 & $<1.00 \mathrm{E}-04$ & 7 & 0.282 & NO \\
\hline PBX3 & 186 & 102 & 0.548 & $<1.00 \mathrm{E}-04$ & 7 & 0.337 & YES \\
\hline ZEB1 & 264 & 139 & 0.527 & $<1.00 \mathrm{E}-04$ & 7 & 0.343 & YES \\
\hline FOXF1 & 62 & 31 & 0.500 & $<1.00 \mathrm{E}-04$ & 7 & 0.312 & YES \\
\hline ZNF532 & 110 & 52 & 0.473 & $<1.00 \mathrm{E}-04$ & 7 & 0.326 & YES \\
\hline
\end{tabular}


Table 1 List of transcription factors differentially expressed between adjacent and healthy mucosa samples (Continued)

\begin{tabular}{|c|c|c|c|c|c|c|c|}
\hline CAMTA1 & 68 & 30 & 0.441 & $<1.00 \mathrm{E}-04$ & 7 & 0.318 & YES \\
\hline JAZF1 & 172 & 74 & 0.430 & $<1.00 \mathrm{E}-04$ & 7 & 0.334 & $\mathrm{NO}$ \\
\hline AFF3 & 31 & 11 & 0.355 & $<1.00 \mathrm{E}-04$ & 7 & 0.295 & YES \\
\hline NFIC & 131 & 43 & 0.328 & $<1.00 \mathrm{E}-04$ & 7 & 0.339 & YES \\
\hline ZEB2 & 74 & 24 & 0.324 & $<1.00 \mathrm{E}-04$ & 7 & 0.324 & YES \\
\hline TCF4 & 408 & 129 & 0.316 & $<1.00 \mathrm{E}-04$ & 6 & 0.371 & YES \\
\hline BCL6 & 36 & 11 & 0.306 & $<1.00 \mathrm{E}-04$ & 7 & 0.309 & NO \\
\hline $\mathrm{NR} 1 \mathrm{H} 4$ & 77 & 22 & 0.286 & $<1.00 \mathrm{E}-04$ & 8 & 0.282 & YES \\
\hline MAFB & 125 & 23 & 0.184 & $<1.00 \mathrm{E}-04$ & 6 & 0.313 & YES \\
\hline HOXB13 & 93 & 14 & 0.151 & $<1.00 \mathrm{E}-04$ & 8 & 0.264 & $\mathrm{NO}$ \\
\hline ATF3 & 4 & 3 & 0.750 & 0.0003 & 10 & 0.184 & $\mathrm{NO}$ \\
\hline ZBTB20 & 149 & 13 & 0.087 & 0.0183982 & 7 & 0.356 & YES \\
\hline THRB & 12 & 2 & 0.167 & 0.0986901 & 8 & 0.259 & YES \\
\hline HOXB6 & 2 & 0 & 0.000 & 1 & 8 & 0.227 & YES \\
\hline IFI16 & 5 & 0 & 0.000 & 1 & 7 & 0.247 & YES \\
\hline NEUROD1 & 12 & 0 & 0.000 & 1 & 8 & 0.236 & $\mathrm{NO}$ \\
\hline
\end{tabular}

The bulk tumor includes a mixture of epithelial and active stromal cells. In order to assess which compartment was predominantly expressing the proteins involved in the identified crosstalk interactions, we used the expression data described by Calon et al. [4] who analyzed profiles of each cell population sorted from human CRC. As a result, the vast majority of genes were over-expressed in the stromal compartment (i.e. collagens, interleukins) indicating their active role in the remodeling of the surrounding microenvironment (Additional file 8: Table S7).

To look for hypothetical relationships explaining the communication loop between TF and membrane receptors activated in CRC-adjacent mucosa, a network using as seed proteins AP-1 and membrane receptors was retrieved. Only experimentally-determined interactions were used to construct this level 1 PPIN (including proteins working as bridges between seed proteins that add information to the studied system). As a result, a strong physical interaction between these two cellular components (the extracellular one and the nuclear one) was found. Twenty-one membrane receptors (out of 22) interact with each other through linker proteins to transduce a cellular signal across the extracellular matrix and membrane, finally activating TF belonging to the AP-1 complex (Additional file 4: Figure S5). It is remarkable the close relationship found between ITGA9, ITGA5, CD36, CD93, TGFBR3 and RECK receptors. Also, this analysis revealed a direct path from ROR2 receptor and the AP-1 transcriptional sub-network, being the ligand WNT5A (up-regulated in tumor tissues) the activator of this signal.

\section{Discussion}

There is clear evidence of the relevance of the tumormicroenvironment crosstalk for carcinogenesis [12-15]. Here we describe altered patterns of expression of the adjacent mucosa from colon cancer patients that could be a direct response against the tumor or induced by the tumor. The analysis of transcriptional profiles and the regulatory networks derived from them allowed us identifying the pathways involved in tumor-microenvironment crosstalk.

We can not discard that at least part of the differences found between adjacent and healthy mucosa were explained by the existence of a pre-neoplastic field in the gut. Studies of adjacent mucosa of the head and neck tumors indicate that such fields can expand more than $7 \mathrm{~cm}$ in diameter [10]. Nevertheless, a study in CRC by Jothy S. et al. reported a gradient of carcinoembryonic antigen (CEA) expression expanding only $5 \mathrm{~cm}$. from the peritumor area [16]. In our study, adjacent tissue from patients was dissected from the proximal tumor resection margin, with a minimum distance of $10 \mathrm{~cm}$. However, a recent paper by Hawthorn et Mojica suggests that the field effect cancerization could be evident up to $10 \mathrm{~cm}$. from the tumor [17].

Previous studies usually have compared paired tumor and adjacent mucosa tissues, which can result in misleading interpretations. We have used a large sample of healthy mucosa as reference for gene expression comparisons and have identified a large number of DEG that can be grouped into three altered patterns: "tumor-like", "trend", and "adjacent-specific". Our conclusion is that adjacent normal mucosa is not so normal. In fact, 


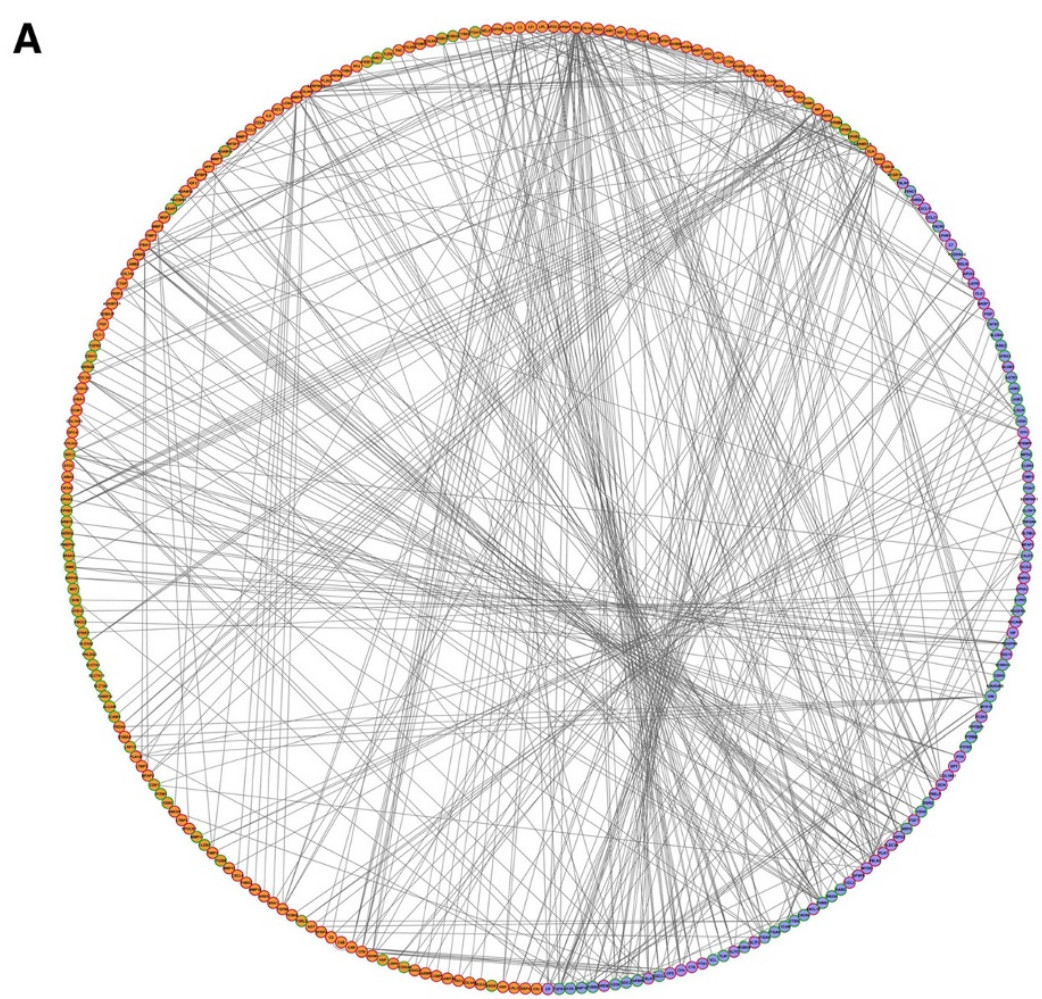

B

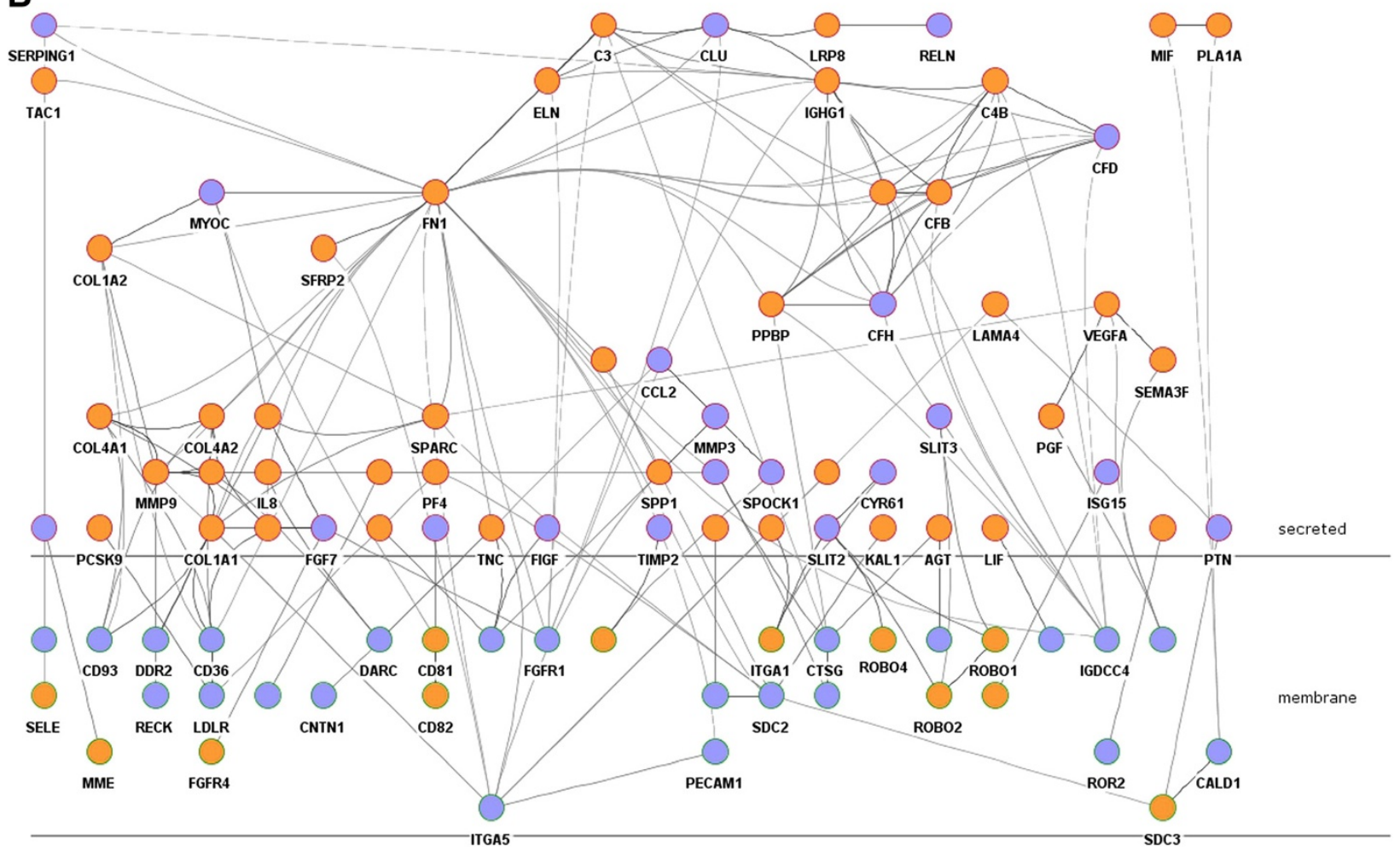

Figure 5 Crosstalk pathway. A. Circular layout of protein-protein interaction network representing interactions (lines) between over-expressed genes in adjacent mucosa (purple) and in tumor (orange). Nodes with a green border symbolize membrane proteins whereas red were used to represent secreted proteins $\mathbf{B}$. Abstraction of the network in which only crosstalk interactions were drawn, using Cerebral view from Cytoscape. 
Table 2 Afferent and efferent pairs in the crosstalk network

\begin{tabular}{|c|c|c|c|}
\hline \multicolumn{4}{|c|}{ AFFERENT PATHWAYS } \\
\hline \multicolumn{2}{|r|}{ SECRETED BY ADJACENT MUCOSA } & \multicolumn{2}{|c|}{ LOCATED IN TUMOR MEMBRANE } \\
\hline Gene symbol & Function & Gene symbol & Function \\
\hline SLIT2 & Cell migration/axon guidance & ITGA1 & $\begin{array}{l}\text { Integrin-mediated cellular signalling and } \\
\text { axon guidance }\end{array}$ \\
\hline SLIT2 & & $\mathrm{ROBO} 2$ & \multirow[t]{4}{*}{ Cell migration/axon guidance } \\
\hline SLIT2 & & $\mathrm{ROBO} 1$ & \\
\hline SLIT3 & & $\mathrm{ROBO} 2$ & \\
\hline SLIT3 & & $\mathrm{ROBO} 1$ & \\
\hline SLIT2 & & $\mathrm{ROBO} 4$ & Cell migration/angiogenesis \\
\hline FGF7 & Growth factor activity & FGFR4 & $\begin{array}{l}\text { Regulation of cell proliferation, } \\
\text { differentiation and migration }\end{array}$ \\
\hline PTN & Growth factor with mitogenic activity & SDC3 & Organization of cell shape \\
\hline TIMP2 & Metalloendopeptidase inhibitor activity & MMP14 & \multirow{2}{*}{$\begin{array}{l}\text { Metalloendopeptidase activit (angiogenesis, } \\
\text { cell proliferation...) }\end{array}$} \\
\hline MMP3 & Regulation of cell migration & MMP14 & \\
\hline SPOCK1 & Cell adhesion & MMP14 & \\
\hline ISG15 & Interferon-mediated signaling pathway & NEDD4 & Virus-host interaction \\
\hline VIP & Intestinal peptide that causes vasodilation & MME & Cellular response to cytokine stimulus \\
\hline MYOC & Anatomical structure morphogenesis & CD81 & Cell proliferation \\
\hline RELN & Neuron migration & LRP8 & \multirow[t]{2}{*}{ Cytokine-mediated signalling pathway } \\
\hline CLU & Platelet and complement activation & LRP8 & \\
\hline SERPING1 & Innate immunity & SELE & Inflammatory response \\
\hline CYR61 & Cell adhesion/chemotaxis & ITGA1 & integrin-mediated signaling pathway \\
\hline FIGF & Angiogenesis & ITGA9 & $\begin{array}{l}\text { Integrin-mediated signaling pathway, } \\
\text { cell adhesion }\end{array}$ \\
\hline HBEGF & Growth factor activity & CD82 & Metastasis suppressor gene \\
\hline CXCL12 & Immune response & CXCR4 & Inflammatory response \\
\hline $\mathrm{CFH}$ & Innate immunity & IGDCC4 & \multirow[t]{2}{*}{ Inmunoglobulin } \\
\hline CFD & Innate immunity & IGDCC4 & \\
\hline \multicolumn{4}{|c|}{ EFFERENT PATHWAYS } \\
\hline \multicolumn{2}{|r|}{ SECRETED BY TUMOR } & \multicolumn{2}{|c|}{ LOCATED IN ADJACENT MUCOSA MEMBRANE } \\
\hline Gene symbol & Function & Gene symbol & Function \\
\hline IL8 & Inflammatory response & DARC & Inflammatory response \\
\hline MIF & Inflammatory response & CALD1 & \multirow[t]{2}{*}{ Cellular component movement } \\
\hline PLA1A & Lipid catabolic process & CALD1 & \\
\hline PF4 & $\begin{array}{l}\text { Immune response and cytokine-mediated } \\
\text { signaling pathway }\end{array}$ & LDLR & Lipid transport and metabolism \\
\hline WNT5A & $\begin{array}{l}\text { In the presence of ROR2, inhibits the canonical } \\
\text { Wnt pathway }\end{array}$ & ROR2 & Wnt receptor signaling pathway \\
\hline REG3A & Inflammatory response & SDC2 & \multirow{5}{*}{$\begin{array}{l}\text { Wound healing/carbohydrate metabolic } \\
\text { process }\end{array}$} \\
\hline SPARC & Regulation of cell proliferation & SDC2 & \\
\hline KAL1 & Extracellular matrix structural constituent & SDC2 & \\
\hline PF4 & $\begin{array}{l}\text { Immune response and cytokine-mediated signaling } \\
\text { pathway }\end{array}$ & SDC2 & \\
\hline FN1 & \multirow{3}{*}{$\begin{array}{l}\text { Extracellular matrix structural constituent involved in } \\
\text { multiple cellular functions }\end{array}$} & SDC2 & \\
\hline FN1 & & ITGA5 & Angiogenesis/cell adhesion/wound healing \\
\hline FN1 & & IGDCC4 & Inmunoglobulin \\
\hline
\end{tabular}


Table 2 Afferent and efferent pairs in the crosstalk network (Continued)

\begin{tabular}{|c|c|c|c|}
\hline FN1 & & CD36 & $\begin{array}{l}\text { Antigen processing and presentation, lipid } \\
\text { storage, cell adhesion }\end{array}$ \\
\hline FN1 & & PECAM1 & Cell adhesion, signal transduction \\
\hline TNC & Guidance of migrating neurons & CNTN1 & Notch signaling pathway, cell adhesion \\
\hline TNC & & ITGA5 & Angiogenesis/cell adhesion/wound healing \\
\hline TNC & & ITGA9 & $\begin{array}{l}\text { Integrin-mediated signaling pathway, } \\
\text { cell adhesion }\end{array}$ \\
\hline COL18A1 & $\begin{array}{l}\text { Inhibits endothelial cell proliferation and } \\
\text { angiogenesis }\end{array}$ & ITGA5 & Angiogenesis/cell adhesion/wound healing \\
\hline SFRP2 & Wnt receptor signaling pathway & ITGA5 & \\
\hline SPP1 & Cell adhesion, response to vitamin $\mathrm{D}$ & ITGA5 & \\
\hline SPP1 & & ITGA9 & $\begin{array}{l}\text { Integrin-mediated signaling pathway, } \\
\text { cell adhesion }\end{array}$ \\
\hline AGT & Renin-angiotensin system & AGTR1 & $\begin{array}{l}\text { Inflammatory response, Rho protein signal } \\
\text { transduction, Renin-angiotensin system }\end{array}$ \\
\hline AGT & & CTSG & Immune response \\
\hline APOC2 & Lipid metabolism & IGDCC4 & Inmunoglobulin \\
\hline PPBP & Chemotaxis and inmune response & IGDCC4 & \\
\hline PPBP & & CTSG & Immune response \\
\hline TAC1 & Peptide which excite neurons, and are potent vasodilators & TACR2 & Response to stress \\
\hline CXCL5 & Chemotaxis and inmune response & DARC & Inflammatory response \\
\hline CCL2 & Chemotaxis and inflammatory response & DARC & \\
\hline C4A & Inflammatory response & IGDCC4 & Inmunoglobulin \\
\hline IGHG1 & Innate inmune response & IGDCC4 & \\
\hline PCSK9 & $\begin{array}{l}\text { Cellular response to starvation/cholesterol } \\
\text { metabolic proces }\end{array}$ & LDLR & Lipid transport and metabolism \\
\hline MMP9 & Proteolysis & ITGA5 & Angiogenesis/cell adhesion/wound healing \\
\hline MMP9 & & RECK & Blood vessel maturation \\
\hline VEGFA & Growth factor active in angiogenesis & NRP2 & Angiogenesis \\
\hline PGF & Growth factor active in angiogenesis & NRP2 & \\
\hline ADAM12 & Epidermal growth factor receptor signaling pathway & ITGA9 & $\begin{array}{l}\text { Integrin-mediated signaling pathway, } \\
\text { cell adhesion }\end{array}$ \\
\hline COL4A1 & Angiogenesis & CD93 & Macrophage activation, cell-cell adhesion \\
\hline COL4A1 & & CD36 & $\begin{array}{l}\text { Antigen processing and presentation, } \\
\text { lipid storage, cell adhesion }\end{array}$ \\
\hline COL1A1 & Positive regulation of cell migration/positive regulation & DDR2 & Cell adhesion, ossification \\
\hline COL1A1 & & ITGA5 & Angiogenesis/cell adhesion/wound healing \\
\hline COL1A1 & & CD93 & Macrophage activation, cell-cell adhesion \\
\hline COL1A1 & & CD36 & $\begin{array}{l}\text { Antigen processing and presentation, lipid } \\
\text { storage, cell adhesion }\end{array}$ \\
\hline COL1A2 & Transforming growth factor beta receptor signaling & CD93 & Macrophage activation, cell-cell adhesion \\
\hline COL1A2 & & CD36 & $\begin{array}{l}\text { Antigen processing and presentation, lipid } \\
\text { storage, cell adhesion }\end{array}$ \\
\hline COL3A1 & $\begin{array}{l}\text { Integrin-mediated signaling pathway/blood vessel } \\
\text { develpment }\end{array}$ & DDR2 & Cell adhesion, ossification \\
\hline COL6A1 & Axon guidance/cell adhesion & CD36 & $\begin{array}{l}\text { Antigen processing and presentation, lipid } \\
\text { storage, cell adhesion }\end{array}$ \\
\hline COL6A3 & Axon guidance/cell adhesion & ITGA5 & Angiogenesis/cell adhesion/wound healing \\
\hline COL4A2 & & CD93 & Macrophage activation, cell-cell adhesion \\
\hline
\end{tabular}


Table 2 Afferent and efferent pairs in the crosstalk network (Continued)

\begin{tabular}{clll}
\hline COL4A2 & Cellular response to transforming growth factor & CD36 & $\begin{array}{l}\text { Antigen processing and presentation, lipid } \\
\text { storage, cell adhesion }\end{array}$ \\
beta stimulus/axon guidance/angiogenesis & Cell adhesion & ITGA5 & Angiogenesis/cell adhesion/wound healing \\
CFB & Complement activation & IGDCC4 & Inmunoglobulin \\
SEMA3F & Cell migration & NRP2 & Angiogenesis \\
EFNA3 & Cell-cell signalling & EPHA3 & Cell adhesion and migration \\
C3 & Complement activation/Fatty acid metabolism & CTSG & Immune response \\
INHBA & Cell surface receptor signaling pathway & TGFBR3 & $\begin{array}{l}\text { Negative regulation of transforming growth } \\
\text { factor beta receptor signaling pathway }\end{array}$ \\
LIF & Growth factor activity & LIFR & Cell proliferation \\
FN1 & Cell adhesion, cell motility, wound healing & FGFR1 & Cell proliferation, differentiation and \\
IGHG1 & Complement activation & FGFR1 & migration \\
ELN & Extracellular matrix organization, cell proliferation & FGFR1 & \\
C3 & Complement activation & FGFR1 & \\
\hline
\end{tabular}

studies that only compare tumor and adjacent mucosa may miss good cancer biomarkers candidates, because many genes are deregulated in adjacent mucosa mimicking the tumor expression.

The predominant functions of DEG are mainly related to response to stimulus, extracellular matrix (ECM) remodeling, organ morphogenesis, and cell adhesion. Remodeling of the ECM network though controlled proteolysis regulates tissue tension, generate pathways for migration, and release ECM protein fragments to direct normal developmental processes such as branching morphogenesis [8]. Collagens are major components of the ECM of which basement membrane type IV and interstitial matrix type I are the most prevalent. Abnormal expression, proteolysis and structure of these collagens influence cellular functions to elicit multiple effects on tumors, including proliferation, initiation, invasion, metastasis, and therapy response [18]. It has been described that integrins that connect various cell types play a vital role in the survival of a growing tumor mass by orchestrating signaling pathways activated through cell-cell and cell-matrix interactions [6]. In our system, integrins ITGA5 and ITGA9 emerged as active signal transducers, occupying central positions in the cellular networks. This result suggests that integrins are not only vital proteins in tumor cells but also in normal-adjacent cells. Moreover, our results indicate that proteins implicated in the described crosstalk are predominantly over-expressed by the tumor stroma. This result underscores the important role of this compartment in CRC carcinogenesis.

One important finding is that DEG are enriched in transcription factors. This indicates the existence of a transcriptional program driving the altered expression pattern observed in adjacent mucosa. A loop including members of the AP-1 family of transcription factors emerged as the most significant one in the analysis. Interestingly, these TF are over-expressed in both adjacent mucosa and tumor tissue. AP-1 members homo or hetero dimerize to assemble the activator protein 1 (AP-1). AP-1 transcription factor acts synergistically with SMAD3/SMAD4 component and is implicated in the regulation of a variety of cellular processes including proliferation and survival, differentiation, growth, apoptosis, cell migration, and inflammation $[19,20]$. Topologically, these nodes have a low centrality but a high eccentricity in the transcriptional network. This result can be a little controversial since it is widely accepted that the more centered a node is the more important their functional role in the studied system [21]. However, a recent publication postulates that nodes with high eccentricity could be quickly activated by external factors [22]. This observation could explain the radial position of AP-1 members Jun, Fos, FosB and JunB into the transcriptional network as important fast effectors mediating response against the tumor.

We hypothesized that cytokines and other signaling proteins secreted by the tumor activate membrane receptors of adjacent mucosa cells that initiate this transcription factor activity. Tumor-secreted growth factors act as paracrine agents distorting the normal tissue homeostasis. In turn, tumors are both maintained or attacked by signals from the surrounding microenvironment inducing stromal reaction, angiogenesis and inflammatory responses. To gain insight into the molecular mechanisms underlying this phenomenon, a bi-tissue PPIN analysis strategy was performed to extract patterns of receptor activation in both directions from adjacent mucosa to tumor and vice-versa. Robo genes appeared as the most recurrently receptors activated 


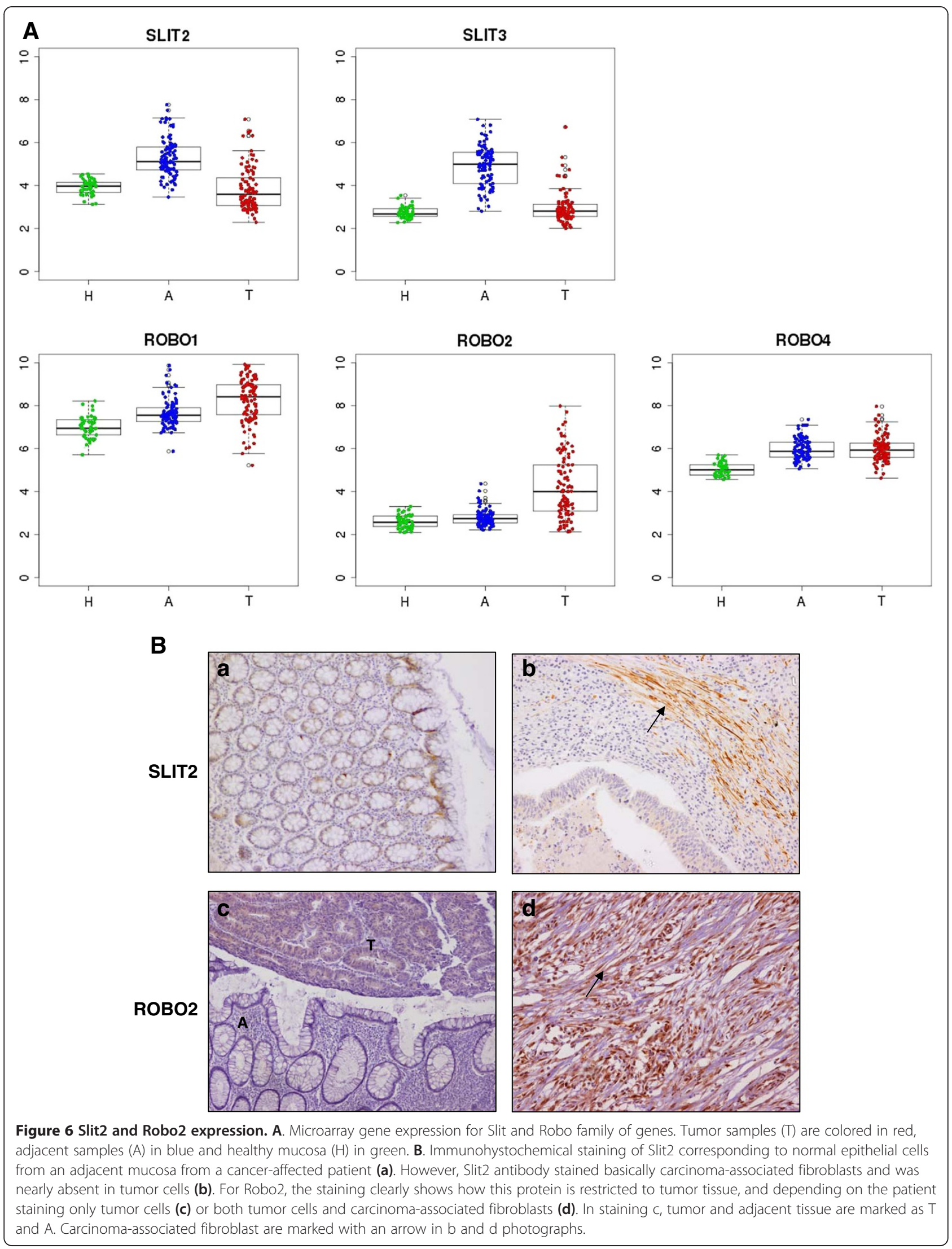


in tumor membrane by Slit family of proteins. Slits have been implicated in regulating a variety of life activities, such as axon guidance, neuronal migration, neuronal morphological differentiation, tumor metastasis, angiogenesis and heart morphogenesis [23]. Several studies have demonstrated dual roles for Slit and Robo in cancer, acting as both oncogenes and tumor suppressors [24]. This bifunctionality is also observed in their roles as axon guidance cues in the developing nervous system, where they both attract and repel neuronal migration [25]. In CRC, Slit2 up-regulation has been reported as beneficial for the overall survival of patients [26]. Slit is under-expressed in patients with metastatic colorectal cancer and their overexpression in cells resulted in an inhibition of cell migration through AKT-GSK3 $\beta$ signaling pathway. In our data, no significant association between Slit2 or Slit3 level of expression and prognosis was found.

CLU-RELN-LRP8 was other afferent axis to consider for further analysis. CLU codifies the protein Clusterin that has been described as both tumor suppressor and pro-survival factor in colon cancer depending on the intra- and extracellular microenvironment crosstalk [27]. In fact, it has been reported that Clusterin is a protein that shares the intracellular information with the microenvironment and it also experiences a systemic diffusion, acting as a factor that synergistically interacts with their surrounding microenvironment [28]. Moreover, it has been proposed as a diagnostic biomarker in colon cancer [29]. The other CRC-mucosa-secreted protein activating LRP8 receptor in tumor is Reelin $(R E L N)$, a glycoprotein that plays an important role in neuronal migration through the activation of lipoproteins receptors such as LRP8 [30]. Also, Reelin has been proposed as a prometastatic factor due to their role in cancer cell migration through TGF- $\beta$ pathway activation [31].

Efferent pathways were also of interest. LIF is a member of the IL6 family of cytokines that displays pleiotropic effects on various cell types and organs [32,33]. In our system, its receptor LIFR was expressed in the colonic epithelium. It has been reported that LIF stimulates the Jak/STAT pathway to produce nitric oxide (NO) [34,35]. Based on this, we hypothesize that, in our model, tumor LIF activates Jak-STAT pathway in normal epithelial cells through LIFR receptor leading to NO release and the subsequent creation of a pro-inflammatory environment. Moreover, in our model, Angiotensinogen (AGT) was produced by the tumor and their receptor (AGTR1) was located in membrane from adjacent tissue. Since Angiotensinogen is the precursor form of the active peptide Angiotensin, the pair AGT-AGTR1 makes up the renin-angiotensin system (RAS), usually associated with cardiovascular homeostasis but recently associated with tumor growth [36]. RAS could play a synergistic effect with LIF inducing NO production, leading to inflammation, macrophage infiltration and tumor-induced fibrosis. In addition to their pro-inflammatory role, it has been reported that NO can activate notch-signaling pathway leading to the induction of tumors [37].

Conceptually, an active sub-network includes differentially expressed and connected proteins in a given phenotype. Here we have described a sub-network including membrane receptors over-expressed in normal adjacent tissue acting together in cell-adhesion and with functions on cell surface signal transduction that finally activate the AP-1 transcription factor. ROR2 has emerged as an important link in the crossroad between cell surface entering signal and Fos/Jun transcriptional role as previously described [38]. ROR2 is tyrosine-kinase receptor that plays an important role in developmental morphogenesis [39] and in our network it was activated by the tumor-secreted WNT5A, a WNT pathway signaling mediator.

We do not exclude the possibility that genes having a pivotal role in crosstalk between adjacent and tumor tissue also have a direct relationship with prognosis. In our data, expression of Fos and Jun were found to be protective when over-expressed in adjacent but not in tumor tissue $(\log$-rank p-value $=0.042)$. Further studies are needed to experimentally corroborate this hypothesis and to test the utility of these transcription factors as prognosis biomarkers. Nevertheless, a complex equilibrium between positively pro-survival and pro-apoptotic signals given by the microenvironment ultimately influences the tumor growth and their plasticity. This could be one of the reasons why prognosis signatures that only take into account tumor but not adjacent tissue expression fail to accurate predict patients' outcome [40].

The study has some methodological and technical limitations. Though we obtained adjacent mucosa from the farthest resection margin and usually required at least $10 \mathrm{~cm}$, it is possible that some of the variability observed among adjacent mucosa might be related to the distance to the tumor that we cannot analyze. Also, despite a careful dissection of tumor blocks before RNA extraction was done, a normal adjacent tissue infiltration can exist in some tumor samples. Regarding analytical methods, the network analysis only considered wellannotated genes. Some TFs were excluded from the transcriptional network analysis due to their low variability in our data. For these reasons, some genes with a putative role in colon tissue remodeling could have been missed. In fact, we did not find TGF- $\beta$, proposed as an important microenvironment modifier [4] because its probeset had very low expression level in our microarray. Finally, our study only included colon specimens, which could raise a concern about generalizability of the results. However, we have previously analyzed that the expression levels are very similar in colon and rectal tumors [41] and this has been confirmed in the TCGA study [42]. 


\section{Conclusions}

In conclusion, gene expression in cells comprising normal adjacent tissue in CRC patients is not so normal and this could have important implications in colorectal cancer prognosis and progression. A systems-level approach has been useful to gain insight into the molecular mechanisms by which adjacent mucosa activates a transcriptomic program in response to cytokines and other signaling proteins secreted by the tumor. We hypothesize that a crosstalk exists, not only between different cell communities within the tumor bulk, but also between colorectal tumor cells and adjacent mucosa, which reacts against the tumor like against a wound. Tumor-secreted growth factors act as paracrine agents distorting the normal tissue homeostasis. In turn, tumors are both maintained and/or attacked by signals from the surrounding microenvironment inducing stromal reaction, angiogenesis and inflammatory responses. Disrupting this intricate molecular network of cell-cell communication and signal transduction could be a therapeutic target in CRC patients.

\section{Methods}

\section{Patients and samples}

A set of 98 paired adjacent normal and tumor tissues from CRC patients and 50 colon mucosa from healthy donors (246 samples in total) were included in this work. Patients were selected to form a homogeneous clinical group of stage II, microsatellite stable (MSS) colorectal tumors. All had been treated with radical surgery, had not received adjuvant therapy and had a minimum follow up of three years. Adjacent normal tissue from patients was dissected from the proximal tumor resection margin with a minimum distance of $10 \mathrm{~cm}$. Healthy donors were invited to participate in this study when they underwent a colonoscopy indicated for screening or symptoms with no evidence of lesions in the colon or rectum (Additional file 9: Table S8). In this paper we use tumor (T), adjacent mucosa (A) and healthy mucosa $(\mathrm{H})$ to designate the different tissue origins for the samples analyzed. All patients were recruited at the Bellvitge University Hospital (Spain) and the Ethics Committee approved the protocol. Written informed consent from patients and healthy donors was required for inclusion in this study.

\section{Differential expression analysis}

RNA extracted from each sample was hybridized in Affymetrix chips Human Genome U219. After a quality control assessment following Affymetrix standards, data was normalized using the RMA algorithm [43]. Both raw and normalized data are available in the NCBI's Gene Expression Omnibus (GEO) database [44] through accession number GSE44076.
Prior to the identification of differentially expressed genes, a filter was applied to remove low variability probes $(n=15,533)$, which mostly corresponded to nonhybridized and saturated measures. The remaining 33,853 probes showed a standard deviation greater than 0.3 and were considered for further analysis. A t-test was used to identify differences in gene expression between apparently normal adjacent mucosa from CRC patients (A) and mucosa from healthy donors $(\mathrm{H})$. A probe was considered differentially expressed when it was significant at 1\% FDR (q-value method) and showed an absolute $\log 2$ mean difference higher than 1 (double expression). The same criteria were applied to identify differentially expressed genes between tumor $(\mathrm{T})$ and healthy mucosa $(\mathrm{H})$.

To attempt a validation of the differentially expressed genes, the same methods were applied to compare samples of healthy colonic mucosa $(\mathrm{n}=13)$ and adjacent mucosa $(n=24)$ extracted from public datasets GSE38713 [45] and GSE23878 [46].

\section{Functional analysis}

Pathway enrichment analysis was performed using two methods. First, Sigora $R$ package [47] was used, which focuses on genes or gene-pairs that are (as a combination) specific to a single pathway. Sigora contains pre-computed data for human pathways in the KEGG [48], BIOCARTA [49], NCI [50], INOH [51] and REACTOME [52] repositories. Second, the gene set enrichment analysis (GSEA) algorithm was also applied, which uses the ranking of differences to identify pathways from a large list of prespecified sets [53].

\section{Analysis of transcription factors}

Transcriptional networks attempt to translate gene expression correlations into transcriptional relationships to reconstruct regulatory loops between transcription factors and their target genes. Transcriptional regulation networks had been previously inferred using the ARACNe algorithm [54], which identifies direct regulatory associations between transcription factors and targets from mutual information measures of co-expression. The associations, represented as a transcriptional network, were used to identify and characterize transcription factors de-regulated in adjacent mucosa from patients when compared to healthy mucosa. Deregulated transcription factors were ranked using a score that took into account both topological parameters of the network and the node expression values. This score divided the number of deregulated nodes linked to each transcription factor by the total number of nodes linked to the transcription factor. To assess statistical significance, a p-value was calculated by resampling 1000 times random lists of genes. For each 
transcription factor, the Network Analyzer module [55] from Cytoscape [56] was used to extract the topological parameters closeness centrality and eccentricity. Only those genes annotated as transcription factor based on experimental data were used in this analysis, whereas those annotated "in silico" were not considered $[57,58]$.

\section{Protein-protein interaction network construction and analysis}

Protein interaction data can be represented as networks were nodes represent proteins and edges represent physical interactions between them. BIANA software (Biological Interactions and Network Analysis) was used to retrieve such networks [59]. BIANA builds networks by selecting interacting partners for an initial set of seed proteins (i.e., the relevant proteins), combining experimentally-determined data from DIP [60], MIPS [61], HPRD [62], BIND [63] and the human interactions from two high-throughput experiments $[64,65]$. The integration of multiple sources of interaction data into a single repository allows working with an extensive set of interactions. For our analysis, only human and experimentally-determined interactions were taken into account. Cytoscape software and its plug-ins were used to analyze and visualize the networks.

\section{Cellular classification of tumor proteins implicated in the crosstalk}

Proteins were classified as "epithelial" or "stromal" on the basis of their gene level of expression in specific cellular subtypes. For this classification, normalized data from the public dataset GSE39396 was used, which included 24 samples corresponding to different human CRC cell populations: epithelial, endothelial, fibroblasts and leukocytes [4].

\section{Immunohistochemistry}

Slices of paraffin-embedded tissue ( $4 \mu \mathrm{m}$ thick) from 5 pairs of matched samples adjacent-mucosa tumor tissue were used. For antigen retrieval, the slides were boiled after deparaffinization in a pressure cooker for 10 minutes in citrated buffer $(8.2 \mathrm{mM}$ tri-sodium citrate and $1.98 \mathrm{mM}$ citric acid, pH6) for Robo2 detection and in EDTA buffer (1 mM EDTA, 0.05\% Tween-20, pH8) for Slit2 detection. Endogenous peroxidase was blocked with $3 \% \mathrm{H}_{2} \mathrm{O}_{2}$ during 20 minutes. After blocking during 30 minutes with $1 / 5$ dilution of goat serum, primary antibodies were incubated overnight at $4^{\circ} \mathrm{C}$. Primary antibodies were rabbit polyclonal against Slit2 (Abcam, ab111128) and rabbit polyclonal against Robo2 (Prestige Antibodies, HPA013371), diluted both 1:100 in antibody diluent (Dako, Copenhagen, Denmark). Reaction was visualized using EnVision antirabbit antibody system, and developed using DAB-Plus Kit
(Dako). Slides were counterstained with Harry's modified haematoxylin. As negative control we used EnVision antirabbit antibody system and displayed no reactivity against any antigen.

\section{Additional files}

Additional file 1: Table S1. List of DEG between adjacent and healthy mucosa.

Additional file 2: Table S2. Sigora functional analysis results. Additional file 3: Table S3. GSEA functional analysis results.

Additional file 4: Figure S1. GSEA representative results. Red and blue bar stands for adjacent and healthy mucosa, respectively. Figure S2. Venn diagram shows the intersection between DEG in our patients series and DEG in the validation series, both at FDR $1 \%$ and FC $>2$ (adjacent vs. healthy mucosa). The heatmap on the right shows how DEG extracted from our discovery set are able to correctly classify healthy and adjacent samples in the validation set. Highlighted in black, the group of adjacent samples showing an extreme phenotype. Figure S3. Transcriptional regulation networks of adjacent (A) and healthy mucosa (B) tissues. Figure S4. GSEA term "Genes with promoter regions [-2 kb,2 kb] around transcription start site containing the motif TGACTCANNSKN which matches annotation for JUN: jun oncogene". Red and blue bar stands for adjacent and healthy mucosa, respectively. Figure S5. Protein-protein interaction network showing the axis membrane receptors - AP-1 transcription factors, activated in adjacent mucosa. Seed proteins are colored in green (transcription factors) or brown (membrane receptors), and highlighted in grey. Inferred interacting proteins are colored in light purple.

Additional file 5: Table S4. Gene expression levels of the 895 DEG between adjacent and mucosa samples, in independent public datasets GSE38713 and GSE23878. Only 825 out of 895 genes were found in the validation serie microarray.

Additional file 6: Table S5. List of significant functions stratified by pattern.

Additional file 7: Table S6. Crosstalk network functional analysis.

Additional file 8: Table S7. Origin of proteins implicated in the crosstalk which are secreted by the tumor or located in tumor membrane.

Additional file 9: Table S8. Baseline characteristics of healthy donors and CRC patients.

\section{Abbreviations}

BIANA: Biological interactions and network analysis; CRC: Colorectal cancer; DEG: Differentially expressed genes; ECM: Extracellular matrix; EMT: Epithelial to mesenchymal transition; DETF: Differentially expressed transcription factors; MSS: Microsatellite stable; PPIN: Protein-protein interaction network; TF: Transcription factor

\section{Competing interest}

The authors have declared that no competing interests exist.

\section{Authors' contributions}

RSP and VM designed the study, conceived the experiments and wrote the article. RSP and AB carried out the experiments. DC performed transcriptional networks. DGM performed inmunohistochemistry and helped to draft the manuscript. XSO, MCB, LPB, and EG analyzed data. CS, JO, XSa, FRM and RS provided samples and clinical data. All authors critically reviewed and had final approval of the article.

\section{Acknowledgements}

We would like to thank Carmen Atencia, Pilar Medina, and Isabel Padrol for her expert assistance. This study was supported by the European Commission grant FP7-COOP-Health-2007-B HiPerDART. Also the Instituto de Salud Carlos III grants (FIS PI08-1635, PI09-01037 and FISPI11-01439), CIBERESP CB07/02/2005, the Spanish Association Against Cancer (AECC) Scientific Foundation, and the Catalan Government DURSI grant 2009SGR1489. Sample collection was 
supported by the Xarxa de Bancs de Tumors de Catalunya sponsored by Pla Director d'Oncología de Catalunya (XBTC).

\section{Author details}

'Unit of Biomarkers and Susceptibility, Catalan Institute of Oncology (ICO), Bellvitge Biomedical Research Institute (IDIBELL) and CIBERESP, L'Hospitalet de Llobregat, Barcelona, Spain. ${ }^{2}$ Translational Research Lab, Catalan Institute of Oncology (ICO), Bellvitge Biomedical Research Institute (IDIBELL), L'Hospitalet de Llobregat, Barcelona, Spain. ${ }^{3}$ Medical Oncology Service, Catalan Institute of Oncology (ICO), Bellvitge Biomedical Research Institute (IDIBELL), L'Hospitalet de Llobregat, Barcelona, Spain. ${ }^{4}$ General and Digestive Surgery Service, University Hospital Bellvitge (HUB-IDIBELL), L'Hospitalet de Llobregat, Barcelona, Spain. ${ }^{5}$ Department of Clinical Sciences, Faculty of Medicine, University of Barcelona (UB), Av. Gran Vía 199-203, 08908 L'Hospitalet de Llobregat, Barcelona, Spain. ${ }^{6}$ Pathology Service, University Hospital Bellvitge (HUB-IDIBELL), Barcelona, L'Hospitalet de Llobregat, Spain. ${ }^{7}$ Department of Gastroenterology, University Hospital Bellvitge (HUBIDIBELL), L'Hospitalet de Llobregat, Barcelona, Spain.

Received: 14 October 2013 Accepted: 19 February 2014

Published: 5 March 2014

\section{References}

1. Hornberg JJ, Bruggeman FJ, Westerhoff HV, Lankelma J: Cancer: a Systems Biology disease. Biosystems 2006, 83:81-90.

2. Hanahan D, Weinberg RA: Hallmarks of cancer: the next generation. Cell 2011, 144:646-674

3. Berdiel-Acer M, Bohem ME, Lopez-Doriga A, Vidal A, Salazar R, Martinez-Iniesta M, Santos C, Sanjuan X, Villanueva A, Mollevi DG: Hepatic carcinoma-associated fibroblasts promote an adaptative response in colorectal cancer cells that inhibit proliferation and apoptosis: nonresistant cells die by nonapoptotic cell death. Neoplasia 2011, 13:931-946.

4. Calon A, Espinet E, Palomo-Ponce S, Tauriello DV, Iglesias M, Cespedes MV, Sevillano M, Nadal C, Jung P, Zhang XH, Byrom D, Riera A, Rossell D, Mangues R, Massague J, Sancho E, Batlle E: Dependency of colorectal cancer on a TGF-beta-Driven program in stromal cells for metastasis initiation. Cancer Cell 2012, 22:571-584.

5. de la Cruz-Merino L, Henao Carrasco F, Vicente Baz D, Nogales Fernandez E, Reina Zoilo JJ, Codes Manuel de Villena M, Pulido EG: Immune microenvironment in colorectal cancer: a new hallmark to change old paradigms. Clin Dev Immunol 2011, 2011:174149.

6. Alphonso A, Alahari SK: Stromal cells and integrins: conforming to the needs of the tumor microenvironment. Neoplasia 2009, 11:1264-1271.

7. Hakansson A, Molin G: Gut microbiota and inflammation. Nutrients 2011, 3:637-682.

8. Egeblad M, Nakasone ES, Werb Z: Tumors as organs: complex tissues that interface with the entire organism. Dev Cell 2010, 18:884-901.

9. Slaughter DP, Southwick HW, Smejkal W: Field cancerization in oral stratified squamous epithelium; clinical implications of multicentric origin. Cancer 1953, 6:963-968.

10. Braakhuis BJ, Tabor MP, Kummer JA, Leemans CR, Brakenhoff RH: A genetic explanation of Slaughter's concept of field cancerization: evidence and clinical implications. Cancer Res 2003, 63:1727-1730.

11. Kitano H: Systems biology: a brief overview. Science 2002, 295:1662-1664

12. Grizzi F, Bianchi P, Malesci A, Laghi L: Prognostic value of innate and adaptive immunity in colorectal cancer. World J Gastroenterol 2013, 19:174-184

13. Kipanyula MJ, Seke Etet PF, Vecchio L, Farahna M, Nukenine EN, Nwabo Kamdje AH: Signaling pathways bridging microbial-triggered inflammation and cancer. Cell Signal 2013, 25:403-416.

14. Malfettone A, Silvestris N, Paradiso A, Mattioli E, Simone G, Mangia A: Overexpression of nuclear NHERF1 in advanced colorectal cancer: association with hypoxic microenvironment and tumor invasive phenotype. Exp Mol Pathol 2012, 92:296-303.

15. Mojica W, Hawthorn L: Normal colon epithelium: a dataset for the analysis of gene expression and alternative splicing events in colon disease. BMC Genomics 2010, 11:5.

16. Jothy S, Slesak B, Harlozinska A, Lapinska J, Adamiak J, Rabczynski J: Field effect of human colon carcinoma on normal mucosa: relevance of carcinoembryonic antigen expression. Tumour Biol 1996, 17:58-64.
17. Hawthorn L, Lan L, Mojica W: Evidence for Field Effect Cancerization in Colorectal Cancer. Genomics 2013, 13:00206-1.

18. Egeblad M, Rasch MG, Weaver VM: Dynamic interplay between the collagen scaffold and tumor evolution. Curr Opin Cell Biol 2010, 22:697-706

19. Eferl R, Wagner EF: AP-1: a double-edged sword in tumorigenesis. Nat Rev Cancer 2003, 3:859-868.

20. Vesely PW, Staber PB, Hoefler G, Kenner L: Translational regulation mechanisms of AP-1 proteins. Mutat Res 2009, 682:7-12.

21. Lu C, Hu X, Wang G, Leach LJ, Yang S, Kearsey MJ, Luo ZW: Why do essential proteins tend to be clustered in the yeast interactome network? Mol Biosyst 2010, 6:871-877.

22. Xu K, Bezakova I, Bunimovich L, Yi SV: Path lengths in protein-protein interaction networks and biological complexity. Proteomics 2011, 11:1857-1867

23. Mehlen P, Delloye-Bourgeois C, Chedotal A: Novel roles for Slits and netrins: axon guidance cues as anticancer targets? Nat Rev Cancer 2011, 11:188-197.

24. Legg JA, Herbert JM, Clissold P, Bicknell R: Slits and Roundabouts in cancer, tumour angiogenesis and endothelial cell migration. Angiogenesis 2008, 11:13-21.

25. Ballard MS, Hinck L: A roundabout way to cancer. Adv Cancer Res 2012 , 114:187-235.

26. Chen WF, Gao WD, Li QL, Zhou PH, Xu MD, Yao LQ: SLIT2 inhibits cell migration in colorectal cancer through the AKT-GSK3beta signaling pathway. Int J Colorectal Dis 2013, 28:933-940.

27. Mazzarelli P, Pucci S, Spagnoli LG: CLU and colon cancer. The dual face of CLU: from normal to malignant phenotype. Adv Cancer Res 2009, 105:45-61.

28. Pucci S, Mazzarelli P, Nucci C, Ricci F, Spagnoli LG: CLU "in and out": looking for a link. Adv Cancer Res 2009, 105:93-113.

29. Rodriguez-Pineiro AM, Garcia-Lorenzo A, Blanco-Prieto S, Alvarez-Chaver P, Rodriguez-Berrocal FJ, Cadena MP, Martinez-Zorzano VS: Secreted clusterin in colon tumor cell models and its potential as diagnostic marker for colorectal cancer. Cancer Invest 2012, 30:72-78.

30. Senturk A, Pfennig S, Weiss A, Burk K, Acker-Palmer A: Ephrin Bs are essential components of the Reelin pathway to regulate neuronal migration. Nature 2011, 472:356-360.

31. Yuan Y, Chen H, Ma G, Cao X, Liu Z: Reelin is involved in transforming growth factor-beta1-induced cell migration in esophageal carcinoma cells. PLoS One 2012, 7:e31802.

32. Mathieu ME, Saucourt C, Mournetas V, Gauthereau X, Theze N, Praloran V, Thiebaud P, Boeuf H: LIF-dependent signaling: new pieces in the Lego. Stem Cell Rev 2012, 8:1-15.

33. Rockman SP, Demmler K, Roczo N, Cosgriff A, Phillips WA, Thomas RJ, Whitehead RH: Expression of interleukin-6, leukemia inhibitory factor and their receptors by colonic epithelium and pericryptal fibroblasts. J Gastroenterol Hepatol 2001, 16:991-1000.

34. Park Jl, Strock CJ, Ball DW, Nelkin BD: The Ras/Raf/MEK/extracellular signal-regulated kinase pathway induces autocrine-paracrine growth inhibition via the leukemia inhibitory factor/JAK/STAT pathway. Mol Cell Biol 2003, 23:543-554.

35. Stempelj M, Kedinger M, Augenlicht L, Klampfer L: Essential role of the JAK/STAT1 signaling pathway in the expression of inducible nitric-oxide synthase in intestinal epithelial cells and its regulation by butyrate. J Biol Chem 2007, 282:9797-9804.

36. Ager El, Neo J, Christophi C: The renin-angiotensin system and malignancy. Carcinogenesis 2008, 29:1675-1684.

37. Charles N, Ozawa T, Squatrito M, Bleau AM, Brennan CW, Hambardzumyan D, Holland EC: Perivascular nitric oxide activates notch signaling and promotes stem-like character in PDGF-induced glioma cells. Cell Stem Cell 2010, 6:141-152.

38. Nomachi A, Nishita M, Inaba D, Enomoto M, Hamasaki M, Minami Y: Receptor tyrosine kinase Ror2 mediates Wnt5a-induced polarized cell migration by activating $\mathrm{c}$-Jun $\mathrm{N}$-terminal kinase via actin-binding protein filamin A.J Biol Chem 2008, 283:27973-27981.

39. Kani S, Oishi I, Yamamoto H, Yoda A, Suzuki H, Nomachi A, lozumi K, Nishita M, Kikuchi A, Takumi T, Minami Y: The receptor tyrosine kinase Ror2 associates with and is activated by casein kinase lepsilon. J Biol Chem 2004, 279:50102-50109.

40. Sanz-Pamplona R, Berenguer A, Cordero D, Riccadonna S, Sole X, Crous-Bou M, Guino E, Sanjuan X, Biondo S, Soriano A, Jurman G, Capella G, Furlanello 
C, Moreno V: Clinical value of prognosis gene expression signatures in colorectal cancer: a systematic review. PLoS One 2012, 7:e48877.

41. Sanz-Pamplona R, Cordero D, Berenguer A, Lejbkowicz F, Rennert H, Salazar R, Biondo S, Sanjuan X, Pujana MA, Rozek L, Giordano TJ, Ben-Izhak O, Cohen $\mathrm{HI}$, Trougouboff P, Bejhar J, Sova Y, Rennert G, Gruber SB, Moreno V: Gene expression differences between colon and rectum tumors. Clin Cancer Res 2011, 17:7303-7312.

42. Network CGA: Comprehensive molecular characterization of human colon and rectal cancer. Nature 2012, 487:330-337.

43. Irizarry RA, Hobbs B, Collin F, Beazer-Barclay YD, Antonellis KJ, Scherf U, Speed TP: Exploration, normalization, and summaries of high density oligonucleotide array probe level data. Biostatistics 2003, 4:249-264.

44. Barrett T, Edgar R: Gene expression omnibus: microarray data storage, submission, retrieval, and analysis. Methods Enzymol 2006, 411:352-369.

45. Planell N, Lozano JJ, Mora-Buch R, Masamunt MC, Jimeno M, Ordas I, Esteller M, Ricart E, Pique JM, Panes J, Salas A: Transcriptional analysis of the intestinal mucosa of patients with ulcerative colitis in remission reveals lasting epithelial cell alterations. Gut 2013, 62:967-976.

46. Uddin S, Ahmed M, Hussain A, Abubaker J, Al-Sanea N, AbdulJabbar A, Ashari LH, Alhomoud S, Al-Dayel F, Jehan Z: Genome-wide expression analysis of Middle Eastern colorectal cancer reveals FOXM1 as a novel target for cancer therapy. Am J Pathol 2011, 178:537-547.

47. Foroushani AB, Brinkman FS, Lynn DJ: Pathway-GPS and SIGORA: identifying relevant pathways based on the over-representation of their gene-pair signatures. PeerJ 2013, 1:e229.

48. Kanehisa M, Goto S: KEGG: kyoto encyclopedia of genes and genomes. Nucleic Acids Res 2000, 28:27-30.

49. Nishimura D: A view from the web BioCarta. Biotech Software \& Internet Report 2004, 2:117-120.

50. Schaefer CF, Anthony K, Krupa S, Buchoff J, Day M, Hannay T, Buetow KH: PID: the Pathway Interaction Database. Nucleic Acids Res 2009, 37:D674-D679.

51. Yamamoto S, Sakai N, Nakamura H, Fukagawa H, Fukuda K, Takagi T: INOH: ontology-based highly structured database of signal transduction pathways. Database (Oxford) 2011, 2011:bar052.

52. Vastrik I, D'Eustachio P, Schmidt E, Gopinath G, Croft D, de Bono B, Gillespie M, Jassal B, Lewis S, Matthews L, Wu G, Birney E, Stein L: Reactome: a knowledge base of biologic pathways and processes. Genome Biol 2007, 8:R39.

53. Subramanian A, Tamayo P, Mootha VK, Mukherjee S, Ebert BL, Gillette MA, Paulovich A, Pomeroy SL, Golub TR, Lander ES, Mesirov JP: Gene set enrichment analysis: a knowledge-based approach for interpreting genome-wide expression profiles. Proc Natl Acad Sci USA 2005, 102:15545-15550

54. Margolin AA, Nemenman I, Basso K, Wiggins C, Stolovitzky G, Dalla Favera R, Califano A: ARACNE: an algorithm for the reconstruction of gene regulatory networks in a mammalian cellular context. BMC Bioinformatics 2006, 7(Suppl 1):S7.

55. Assenov Y, Ramirez F, Schelhorn SE, Lengauer T, Albrecht M: Computing topological parameters of biological networks. Bioinformatics 2008, 24:282-284

56. Shannon P, Markiel A, Ozier O, Baliga NS, Wang JT, Ramage D, Amin N, Schwikowski B, Ideker T: Cytoscape: a software environment for integrated models of biomolecular interaction networks. Genome Res 2003, 13:2498-2504.

57. Vaquerizas JM, Kummerfeld SK, Teichmann SA, Luscombe NM: A census of human transcription factors: function, expression and evolution. Nat Rev Genet 2009, 10:252-263.

58. Wingender E, Schoeps T, Donitz J: TFClass: an expandable hierarchical classification of human transcription factors. Nucleic Acids Res 2013, 41:D165-D170.

59. Garcia-Garcia J, Guney E, Aragues R, Planas-Iglesias J, Oliva B: Biana: a software framework for compiling biological interactions and analyzing networks. BMC Bioinformatics 2010, 11:56.

60. Xenarios I, Fernandez E, Salwinski L, Duan XJ, Thompson MJ, Marcotte EM, Eisenberg D: DIP: The database of interacting proteins: 2001 update. Nucleic Acids Res 2001, 29:239-241.

61. Pagel P, Kovac S, Oesterheld M, Brauner B, Dunger-Kaltenbach I, Frishman G, Montrone C, Mark P, Stumpflen V, Mewes HW, Ruepp A, Frishman D: The MIPS mammalian protein-protein interaction database. Bioinformatics 2005, 21:832-834.
62. Peri S, Navarro JD, Kristiansen TZ, Amanchy R, Surendranath V, Muthusamy B, Gandhi TK, Chandrika KN, Deshpande N, Suresh S, Rashmi BP, Shanker K, Padma N, Niranjan V, Harsha HC, Talreja N, Vrushabendra BM, Ramya MA, Yatish AJ, Joy M, Shivashankar HN, Kavitha MP, Menezes M, Choudhury DR, Ghosh N, Saravana R, Chandran S, Mohan S, Jonnalagadda CK, Prasad CK: Human protein reference database as a discovery resource for proteomics. Nucleic Acids Res 2004, 32:D497-D501.

63. Alfarano C, Andrade CE, Anthony K, Bahroos N, Bajec M, Bantoft K, Betel D, Bobechko B, Boutilier K, Burgess E, Cavero R, D'Abreo C, Donaldson I, Dorairajoo D, Dumontier MJ, Dumontier MR, Earles V, Farrall R, Feldman $H$, Garderman E, Gong Y, Gonzaga R, Grytsan V, Gryz E, Gu V, Haldorsen E, Halupa A, Haw R, Hrvojic A: The Biomolecular Interaction Network Database and related tools 2005 update. Nucleic Acids Res 2005, 33:D418-D424.

64. Rual JF, Venkatesan K, Hao T, Hirozane-Kishikawa T, Dricot A, Li N, Berriz GF, Gibbons FD, Dreze M, Ayivi-Guedehoussou N, Klitgord N, Simon C, Boxem M, Milstein S, Rosenberg J, Goldberg DS, Zhang LV, Wong SL, Franklin G, Li S, Albala JS, Lim J, Fraughton C, Llamosas E, Cevik S, Bex C, Lamesch P, Sikorski RS, Vandenhaute J, Zoghbi HY: Towards a proteome-scale map of the human protein-protein interaction network. Nature 2005, 437:1173-1178.

65. Stelzl U, Worm U, Lalowski M, Haenig C, Brembeck FH, Goehler H, Stroedicke M, Zenkner M, Schoenherr A, Koeppen S, Timm J, Mintzlaff S, Abraham C, Bock N, Kietzmann S, Goedde A, Toksoz E, Droege A, Krobitsch S, Korn B, Birchmeier W, Lehrach H, Wanker EE: A human protein-protein interaction network: a resource for annotating the proteome. Cell 2005, 122:957-968.

doi:10.1186/1476-4598-13-46

Cite this article as: Sanz-Pamplona et al:: Aberrant gene expression in mucosa adjacent to tumor reveals a molecular crosstalk in colon cancer. Molecular Cancer 2014 13:46.

\section{Submit your next manuscript to BioMed Central and take full advantage of:}

- Convenient online submission

- Thorough peer review

- No space constraints or color figure charges

- Immediate publication on acceptance

- Inclusion in PubMed, CAS, Scopus and Google Scholar

- Research which is freely available for redistribution 